\title{
Expression of TSG101 protein and LSF transcription factor in HPV-positive cervical cancer cells
}

\author{
JUSTYNA K. BRONIARCZYK ${ }^{1}$, ALICJA WAROWICKA ${ }^{2}$, ANNA KWAŚNIEWSKA ${ }^{3}$, \\ MARIA WOHUN'-CHOLEWA ${ }^{4}$, WOJCIECH KWAŚNIEWSKI ${ }^{5}$ and ANNA GOŹDZICKA-JÓZEFIAK ${ }^{1}$ \\ ${ }^{1}$ Department of Molecular Virology, ${ }^{2}$ NanoBioMedical Centre, Adam Mickiewicz University, Poznań 61-614; \\ ${ }^{3}$ Department of Obstetrics and Gynecology, Medical University of Lublin, Lublin 20-081; \\ ${ }^{4}$ Department of Cell Biology, University of Medical Science, Poznan 60-806; \\ ${ }^{5}$ First Department of Oncological Gynecology and Gynecology, \\ Medical University of Lublin, Lublin 20-081, Poland
}

Received June 27, 2013; Accepted January 7, 2014

DOI: $10.3892 / \mathrm{ol} .2014 .1967$

\begin{abstract}
Our previous study demonstrated a decreased expression of tumor susceptibility gene 101 (TSG101) in cervical cancer cells. To identify the mechanism responsible for TSG101 downregulation during cervical cancer development, we analyzed the TSG101 promoter using cis-element cluster finder software. One of the transcription factors whose binding site was detected in the TSG101 promoter was late SV40 factor (LSF). The aim of this study was to analyze the TSG101 protein and LSF expression levels during cervical cancer development. Immunohistochemical analysis confirmed a previously observed decreased expression of TSG101, whereas quantitative polymerase chain reaction (qPCR) and immunohistochemistry analysis revealed high expression of LSF in cervical, precancer and cancer cells compared with human papillomavirus (HPV)-negative non-cancer samples. High expression of LSF in cervical cancer HPV-positive cells suggests that this protein may be important in the regulation of TSG101 expression, as well as in cervical carcinogenesis. The role of LSF as a mediator in cervical cancer development must be confirmed in future studies.
\end{abstract}

\section{Introduction}

Human papillomavirus (HPV)-mediated transformation of human cervical epithelial cells has been recognized as a multi-step process in which not only viruses but also certain additional unknown factors and (epi)genetic events are required.

Correspondence to: Dr Justyna K. Broniarczyk, Department of Molecular Virology, Institute of Experimental Biology, Adam Mickiewicz University, Umultowska 89, Poznan 61-614, Poland E-mail: justekbr@amu.edu.pl

Key words: LSF transcription factor, TSG101 protein, cervical cancer
Our previous study indicated that one of the factors that may be involved in cervical carcinogenesis is tumor susceptibility gene 101 (TSG101) (1). The TSG101 gene was mapped to chromosome 11.p15.1-p15.2., a region that is associated with the loss of heterozygosity in several tumor types, including breast cancer and cervical cancer $(2,3)$. The TSG101 protein is involved in a variety of important biological functions, such as ubiquitination, transcriptional regulation, endosomal trafficking, virus budding, proliferation and cell survival (4-16). It has been suggested that TSG101 is an important factor for maintaining cellular homeostasis and that perturbation of TSG101 functions leads to transformation (17). To identify the mechanism responsible for TSG101 downregulation during cervical cancer development, we analyzed the TSG101 promoter using cis-element cluster finder (Cister) software. One of the transcription factors, whose binding site was detected in the TSG101 promoter, was LSF (1).

LSF was initially identified due to its ability to activate a major late Simian virus 40 (SV40) promoter (18). Late SV40 factor (LSF) is commonly named as CP2 and is encoded by the TFCP 2 gene located in chromosome 12q13 $(19,20)$. LSF belongs to an evolutionary conserved family of transcription factors consisting of two subfamilies: LSF/CP2 and grainyhead (21-24).

Human LSF is a 502-amino acid protein with a molecular weight of $\sim 57 \mathrm{kDa}$ (24). It consists of two functional domains. The N-terminal domain is a DNA interaction region located between amino acids 67 and 260, and is similar in structure to $\mathrm{p} 53 / \mathrm{p} 63 / \mathrm{p} 73$ DNA binding domain. The $\mathrm{C}$-terminal region is responsible for oligomerization and contains tetramerization and dimerization domains. The tetramerization domain is located between amino acids 326 and 89, and is structurally similar to the sterile $\alpha$-motif protein-protein interaction domain $(24,25)$. The dimerization domain contains residues 448-502 and is structurally similar to the ubiquitin-like fold domain (24-26). Amino acid residues 189-239 mediate nuclear localization of LSF $(24,27,28)$.

With the exception of its important role in regulation of viral and cellular promoters, including SV40, and HIV-1 promoters, including fibrinogen and $\alpha$-globin, LSF is involved in numerous other important biological functions, 
such as regulation of the cell cycle, cell growth and development, DNA synthesis, cell survival and Alzheimer's disease. Moreover, LSF also functions as an anti-apoptotic factor $(24,29,30)$.

The aim of the present study was to analyze TSG101 and LSF protein expression during cervical cancer development.

\section{Materials and methods}

Clinical samples. Samples were collected from 116 patients (median age, 49 years; range, 23-61 years) undergoing gynecological surgical procedures at the Department of Obstetrics and Pathology of Pregnancy, Medical University (Lublin, Poland). The study group consisted of 29 HPV-positive cervical samples (carcinoma colli uteri/squamous cell carcinoma), $30 \mathrm{HPV}$-positive high-grade squamous intraepithelial lesion (HSIL) samples, 28 HPV-positive low-grade squamous intraepithelial lesion (LSIL) samples and 29 histopathologically normal, HPV-negative cervical tissues obtained from women undergoing treatment for reasons other than cervical cancer. The study was approved by the Ethics Committee of the Medical University of Lublin. For cancer and neoplastic localization, all specimens initially underwent hematoxylin and eosin staining followed by a pathological review. Cervical sections comprising $\geq 70 \%$ cancer cells were used as cancer samples. The tissue samples were frozen immediately in liquid nitrogen and stored at $-80^{\circ} \mathrm{C}$ until further analysis. Patients provided written informed consent.

Isolation of DNA. Total DNA was isolated from study cells using a QIAmp DNA Midi kit (Qiagen, Hilden, Germany) according to the manufacturer's instructions.

Identification of HPV DNA. HPV DNA was identified by polymerase chain reaction (PCR) amplification of the HPV gene sequence using isolated DNA and primers: MY09, MY11 (31) and LC1, and LC2 (32), complementary to the genome sequence of the majority of common types of HPV viruses, as described previously $(31,32)$.

RNA extraction/isolation. Total RNA was isolated from normal, dysplastic (LSIL and HSIL) and cancer tissues using an RNeasy Mini kit (Qiagen) following the manufuacturer's instructions. DNA was removed by DNase treatment (RNase-Free DNase set, Qiagen).

Quantitative PCR (qPCR) analysis. Total RNA $(1 \mu \mathrm{g})$ was reverse transcribed to cDNA using the QuantiTect Reverse Transcription kit (Qiagen). PCR reactions were run under the following conditions: pre-denaturation at $95^{\circ} \mathrm{C}$ for $5 \mathrm{~min}$, then 40 cycles at $95^{\circ} \mathrm{C}$ for $10 \mathrm{sec}, 63.8^{\circ} \mathrm{C}$ for $20 \mathrm{sec}, 72^{\circ} \mathrm{C}$ for $20 \mathrm{sec}$ and a final extension at $72^{\circ} \mathrm{C}$ for 6 min. qPCR was performed on a Corbett Rotor-Gene 6000 (Corbett Life Science, Concorde, NSW, Australia).

PCR was performed using SYBR Green PCR master mix (Invitrogen Life Technologies, Carlsbad, CA, USA) and appropriate primers (forward, 5'TGGCCGACGAAGTGATTGAA $3^{\prime}$ and reverse, 5'GGGCAATGCAAGGACATCAC 3 ' for the LSF gene). Total cDNA $(2 \mu \mathrm{l})$ and primers were added to $8 \mu \mathrm{l}$ Power SYBR Green PCR master mix.
Table I. Position and probability of LSF transcription factor binding to TSG101 promoter sequence according to Cister software.

\begin{tabular}{lclc}
\hline Position & Strand & Sequence & Probablility \\
\hline $3262-3276$ & + & agtggcttacgcctg & 0.56 \\
$5238-5252$ & - & ccggccagccaagc & 0.49 \\
$1158-1172$ & - & ccactgcactccagc & 0.48 \\
$3398-3412$ & + & ggtggtgggcacctg & 0.31 \\
$3293-3307$ & + & gcaggctgaggcggg & 0.27 \\
$1333-1347$ & - & ctactgcactccagc & 0.24 \\
$5174-5188$ & + & gctgcgacgcgctcg & 0.21 \\
$1125-1139$ & + & ggtaggtggagcttg & 0.19 \\
$5064-5078$ & - & ctggggcagcccagc & 0.17 \\
$5233-5247$ & - & ccgtcccggcccagc & 0.14 \\
$5053-5067$ & + & tgtgggacggtctgg & 0.13 \\
$3493-3507$ & - & ctatcgcactccagc & 0.12 \\
$6654-6668$ & - & caggcgtgagccacc & 0.12 \\
$1063-1077$ & + & ggtggcaggtgcctg & 0.10 \\
\hline
\end{tabular}

LSF, late SV40 factor; TSG101, tumor susceptibility gene 101.

Glyceraldehyde 3-phosphate dehydrogenase (GAPDH) was used as reference gene (33). All reactions for samples and housekeeping genes were run in triplicate.

Immunohistochemical analysis of TSG101 and LSF expression. Immunohistochemical analysis was prepared using a LSAB System-HRP visualization kit (K0679; Dako, Carpinteria, CA, USA), mouse monoclonal anti-TSG101 antibody (Santa Cruz Biotechnology, Inc., Santa Cruz, CA, USA) and mouse monoclonal anti-LSF antibody (BD Transduction Laboratories ${ }^{\mathrm{TM}}$, San Jose, CA, USA). Antibodies were diluted in Dako antibody diluent with background-reducing component (S3022; Dako).

Immunohistochemical evaluations of TSG101 and LSF expression were performed independently by two pathomorphologists. The cells were counted on an Axiophote (Opton) fluorescence microscope (Carl Zeiss, Oberkochen, Germany) with $\times 200$ magnification on a field of 16 squares ( $4 \times 4$ squares), which corresponded to an area of $0.25 \mathrm{~mm}^{2}(0.5 \times 0.5 \mathrm{~mm})$.

Positive staining was scored according to the percentage of cells with positive staining and staining intensity. Measurement of immunoreactive cells was performed using Cell-2 software, version 4.1 (University of Medical Sciences, Poznan, Poland). The quantitative method is based on the analysis of the color distribution and the optical density. The software identifies cells with a greater optical density than the background and, on the basis of the color ratio, classifies cells as immunoreactive. To determine the percentage of positive cells in the sections, the counts of immunopositive cells were divided by the total cell count. For each case, a minimum of 5,000 total cells were counted in a single section.

Statistical analysis. Data were analyzed with Statistica software, version 6.1. (Statsoft, Krakow, Poland). Statistical significance was analyzed using Kruskal-Wallis with post-hoc 
Table II. Characteristics of the studied group.

\begin{tabular}{lcccc}
\hline $\begin{array}{l}\text { Clinical } \\
\text { characteristics }\end{array}$ & Control & HSIL & LSIL & $\begin{array}{c}\text { Cervical } \\
\text { cancer }\end{array}$ \\
\hline HPV detection & - & + & + & + \\
Number of patients & 29 & 30 & 28 & 29 \\
\hline
\end{tabular}

HSIL, high-grade squamous intraepithelial lesion; LSIL, low-grade squamous intraepithelial lesion; HPV, human papillomavirus.

A

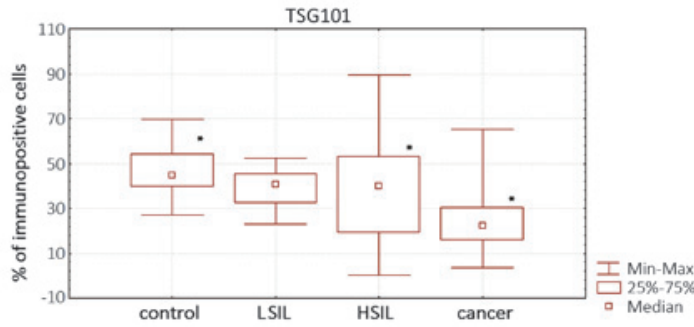

B

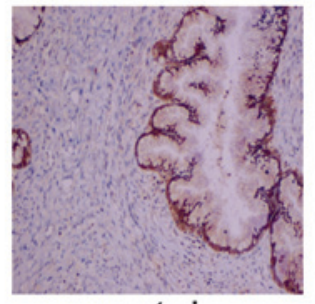

control
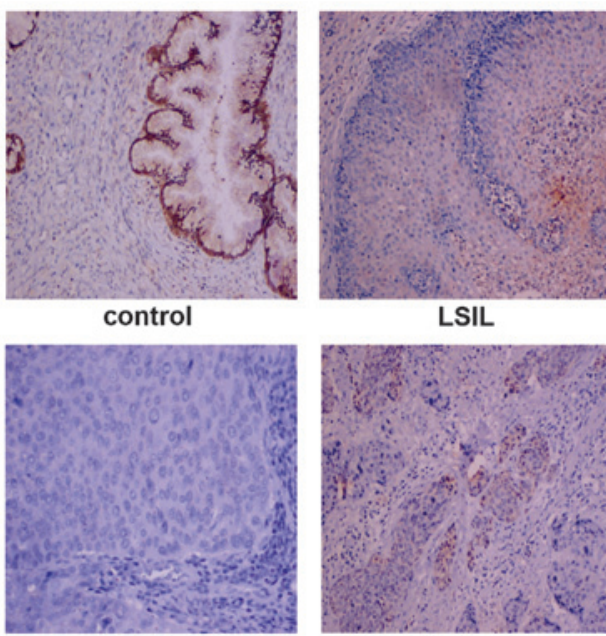

HSIL

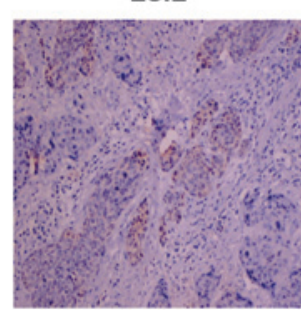

Cervical cancer

Figure 1. (A) Quantitative and (B) qualitative analysis of immunohistochemical staining for TSG101 (magnification, $\mathrm{x} 200$ ). ${ }^{*} \mathrm{P}<0.05$ compared with non-tumor (HPV-negative) cells. HSIL, high-grade squamous intraepithelial lesion; LSIL, low-grade squamous intraepithelial lesion.

Dunn's test (immunohistochemistry) and one-way analysis of variance with Tukey's post hoc test (qPCR). The difference was considered to be statistically significant when P-values were $<0.05$.

Bioinformatics analysis. The localization and frequency of LSF binding sites in the TSG101 promoter sequence were analyzed using Cister software (Zlab gene regulation tools, Boston Univeristy, Boston, MA, USA) as described previously (1).

\section{Results}

Bioinformatics analysis of LSF binding site frequency in the TSG101 promoter sequence. Analysis using Cister software distinguished 14 binding sites for LSF transcription factor in the TSG101 promoter sequence (Table I).
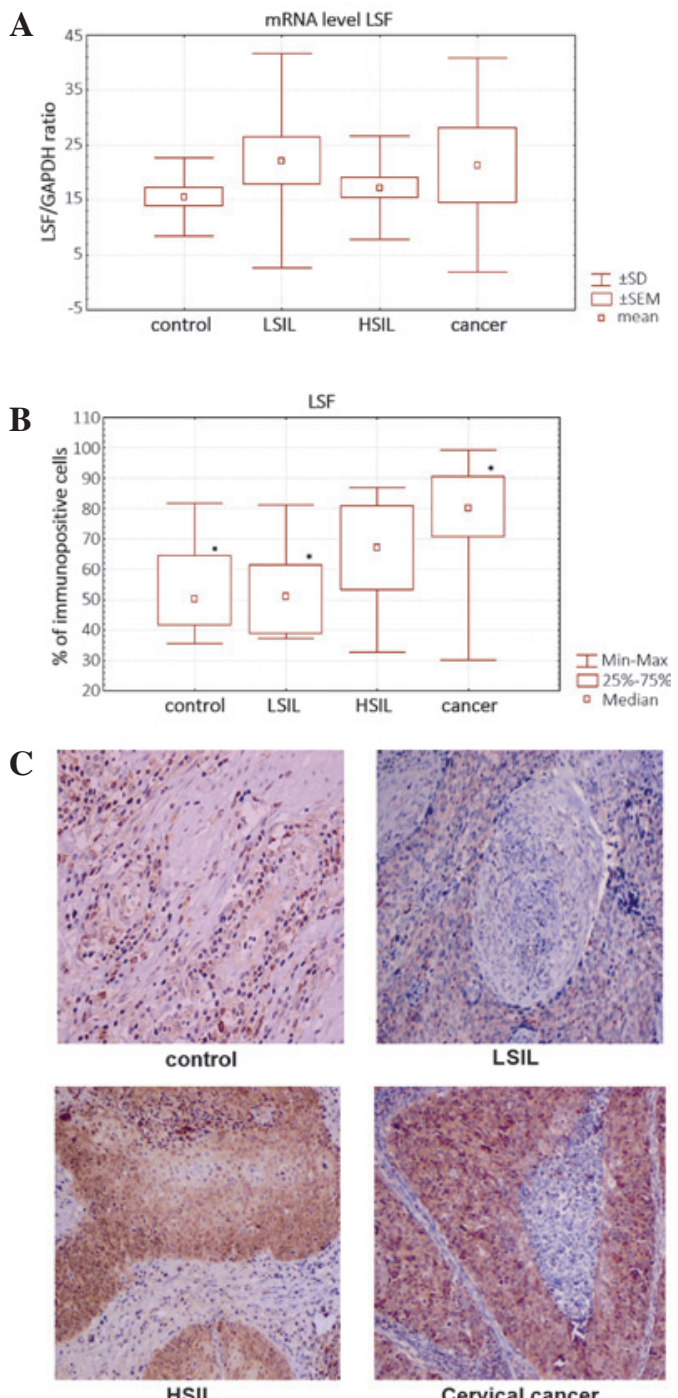

Figure 2. LSF mRNA level in HPV-negative non-tumor controls and LSIL, HSIL and HPV-positive cervical cancer epithelial cells. The $L S F$ mRNA levels were determined by quantitative polymerase chain reaction analysis of cDNA. (A) Copy number of $L S F$ transcripts was normalized to GAPDH expression level. (B) Quantitative and (C) qualitative analysis of immunohistochemical staining for LSF (magnification $\mathrm{x} 200$ ). ${ }^{*} \mathrm{P}<0.05$ compared with non-tumor (HPV-negative) cells. LSF, late SV40 factor; HPV, human papillomavirus; HSIL, high-grade squamous intraepithelial lesion; LSIL, low-grade squamous intraepithelial lesion, GAPDH, glyceraldehyde 3-phosphate dehydrogenase.

Detection of HPV viruses in clinical samples. Prior to molecular analysis, clinical samples were screened for the presence of HPV viruses. Only HPV-positive HSIL, LSIL and cancer cells, and the HPV-negative control, were used in these studies (Table II).

Immunohistochemical analysis of TSG101 expression. Quantitive immunohistochemical analysis based on the percentage of TSG101-immunopositive cells revealed a significantly $(\mathrm{P}<0.05)$ lower percentage of TSG101-immunopositive cells in cervical cancer and HSIL samples compared with that in non-tumor (HPV-negative) cells (Fig. 1A). The TSG101 protein showed mainly nuclear localization (Fig. 1B).

Analysis of LSF $m R N A$ and protein level. qPCR analysis showed an increased level of $L S F$ mRNA in dysplastic 
(LSIL and HSIL) and cervical cancer cells. LSF mRNA level was upregulated to $42.43 \%$ in HSIL samples, $30.6 \%$ in LSIL samples and $37.54 \%$ in cancer samples, compared with that in non-tumor HPV-negative samples (Fig. 2A). The differences in LSF expression were not statistically significant $(\mathrm{P}>0.05)$.

Quantitive immunohistochemical analysis based on the percentage of LSF-immunopositive cells confirmed the increased expression of LSF in cervical cancer cells.

The percentage of LSF-immunostained cells was significantly higher in cervical cancer and LSIL samples compared with that in HPV-negative non-tumor controls $(\mathrm{P}<0.05)$ (Fig. 2B). LSF was observed mainly in the nucleus (Fig. 2C).

\section{Discussion}

In addition to HPV viruses, numerous factors, such as oncogenes and tumor suppressor genes are involved in cervical cancer development.

Our previous results demonstrated a decreased expression of TSG101 in cervical cancer cells (1). In the present study, we confirmed TSG101 protein downregulation during cervical cancer development using immunohistochemical analysis.

TSG101 is constitutively expressed in a number of human tissues (34). However, upregulation of TSG101 was found in thyroid papillary carcinomas, and breast, ovarian and gastrointestinal tumors, while downregulation of TSG101 was observed in endometrial and cervical cancers $(1,35,36)$.

Our bioinformatics analysis showed that one of the factors that may bind with the TSG101 promoter and regulate its expression is LSF.

qPCR and immunohistochemical analysis revealed high expression levels of LSF in cervical cancer cells compared with non-cancer samples. These results suggest that LSF is important in cervical tumorigenesis and that LSF mRNA levels generally do not fluctuate. LSF mRNA has been suggested to be a normalization control in gene expression profiling (37). LSF is also expressed ubiquitously in cell lines and in the developing mouse, and protein levels are unaltered during cell cycle progression (38-40).

LSF is a transcription factor involved in the regulation of a variety of viral and cellular promoters. It acts as a transcription activator and repressor (24). LSF stimulates transcription of the SV40 late promoter (18). It also binds to the sequence within the HIV-1 long terminal repeat (LTR) initiation region and recruits YY1 and histone deacetylase 1 to the LTR, inhibiting transcription and thereby contributing to HIV persistence within resting CD4 T cells (41). The cellular factor YY1 also plays a critical role in tumorigenesis and HPV infection, as a positive and negative regulator of cellular and viral gene expression. The YY1-mediated downregulation of HPV transcription, as well as other promoters, act together with LSF (42).

High expression of LSF in cervical cancer HPV-positive cells suggests that this protein may be involved in downregulation of the TSG101 gene promoter and HPV-dependent cervical carcinogenesis. Fan et al identified LSF as a downstream mediator of Notch1 signaling and showed that LSF mediates, at least in part, Notch-1-induced carcinogenesis (43). Notch genes encode heterodimeric transmembrane receptors, which play a critical role in maintaining the balance between cell proliferation, differentiation and apoptosis. Aberrant Notch signaling may contribute to cervical carcinogenesis (44), head and neck cancer (45), lung cancer (46), colon cancer (47), acute myeloid leukemia (48) and diffuse large B-cell lymphoma (30). LSF was also significantly upregulated in hepatocellular carcinoma compared with non-cancer samples (43). In liver cancer, its expression is strongly correlated with tumor grade and aggressiveness (49). Microarray studies revealed that LSF modulated the expression of specific genes involved in regulating invasion, angiogenesis, chemoresistance and senescence (24). It has been suggested that LSF may function as an oncogene in hepatocarcinogenesis $(29,30,50)$. Osteopontin, matrix metalloproteinase 9, c-Met and complement factor $\mathrm{H}$ have been identified as a proteins directly regulated by LSF and involved in hepatocarcinogenesis (24).

A major cellular target of LSF is the thymidylate synthase gene, which encodes the enzyme involved in the production of dTTP, required for DNA synthesis. Deregulated LSF expression may facilitate entry into the G1/S phase of the cell cycle, promote DNA synthesis, stimulate transformation and facilitate cancer cell survival. Inhibition of LSF results in either apoptosis during $\mathrm{S}$ phase or cell cycle arrest at the G1/S transition $(29,30,50)$.

The role of LSF as a mediator in cervical cancer development must be confirmed in future studies.

\section{Acknowledgements}

This study was supported by a grant (N N401 012136) from the Ministry of Science and Higher Education in Poland.

\section{References}

1. Broniarczyk J, Olejnik-Schmidt AK, Luczak MW, Schmidt MT, Dabrowski M, Józefiak A, Kedzia W, Kwaśniewska A and Goździcka-Józefiak A: Analysis of expression and structure of the TSG101 gene in cervical cancer cells. Int J Mol Med 25: 777-783, 2010

2. Li L, Li X, Francke U and Cohen SN: The TSG101 tumor susceptibility gene is located in chromosome 11 band p15 and is mutated in human breast cancer. Cell 88: 143-154, 1997.

3. Singh RK, Dasgupta S, Bhattacharya N, Chunder N, Mondal R, Roy A, Mandal S, Roychowdhury S and Panda CK: Deletion in chromosome 11 and Bcl-1/Cyclin D1 alterations are independently associated with the development of uterine cervical carcinoma. J Cancer Res Clin Oncol 131: 395-406, 2005.

4. Carstens MJ, Krempler A, Triplett AA, Van Lohuizen M and Wagner KU: Cell cycle arrest and cell death are controlled by p53-dependent and p53-independent mechanisms in Tsg101-deficient cells. J Biol Chem 279: 35984-35994, 2004.

5. Koonin EV and Abagyan RA: TSG101 may be the prototype of a class of dominant negative ubiquitin regulators. Nat Genet 16: 330-331, 1997.

6. Ponting CP, Cai YD and Bork P: The breast cancer gene product TSG101: a regulator of ubiquitination? J Mol Med 75: 467-469, 1997.

7. Watanabe M, Yanagi Y, Masuhiro Y, Yano T, Yoshikawa H, Yanagisawa J and Kato S: A putative tumor suppressor, TSG101, acts as a transcriptional suppressor through its coiled-coil domain. Biochem Biophys Res Commun 245: 900-905, 1998

8. Hittelman AB, Burakov D, Iñiguez-Lluhí JA, Freedman LP and Garabedian MJ: Differential regulation of glucocorticoid receptor transcriptional activation via $\mathrm{AF}-1$-associated proteins. EMBO J 18: 5380-5388, 1999.

9. Babst M, Odorizzi G, Estepa EJ and Emr SD: Mammalian tumor susceptibility gene 101 (TSG101) and the yeast homologue, Vps23p, both function in late endosomal trafficking. Traffic 1:248-258, 2000.

10. Garrus JE, von Schwedler UK, Pornillos OW, et al: Tsg101 and the vacuolar protein sorting pathway are essential for HIV-1 budding. Cell 107: 55-65, 2001. 
11. Lu Q, Hope LW, Brasch M, Reinhard C and Cohen SN: TSG101 interaction with HRS mediates endosomal trafficking and receptor down-regulation. Proc Natl Acad Sci USA 100: 7626-7631, 2003

12. Bache KG, Brech A, Mehlum A and Stenmark H: Hrs regulates multivesicular body formation via ESCRT recruitment to endosomes. J Cell Biol 162: 435-442, 2003.

13. Zhong Q, Chen Y, Jones D and Lee WH: Perturbation of TSG101 protein affects cell cycle progression. Cancer Res 58: 2699-2702, 1998.

14. Xie W, Li L and Cohen SN: Cell cycle-dependent subcellular localization of the TSG101 protein and mitotic and nuclear abnormalities associated with TSG101 deficiency. Proc Nat Acad Sci USA 95: 1595-1600, 1998.

15. Ruland J, Sirard C, Elia A, MacPherson D, Wakeham A, Li L, de la Pompa JL, Cohen SN and Mak TW: p53 accumulation, defective cell proliferation, and early embryonic lethality in mice lacking tsg101. Proc Natl Acad Sci USA 98: 1859-1864, 2001

16. Krempler A, Henry MD, Triplett AA and Wagner KU: Targeted deletion of the Tsg101 gene results in cell cycle arrest at G1/S and p53-independent cell death. J Biol Chem 277: 43216-43223, 2002.

17. Wagner KU, Krempler A, Qi Y, Park K, Henry MD, Triplett AA, Riedlinger G, Rucker EB and Hennighausen L: Tsg 101 is essential for cell growth, proliferation, and cell survival of embryonic and adult tissues. Mol Cell Biol 23: 150-162, 2003.

18. Kim CH, Heath C, Bertuch A and Hansen U: Specific stimulation of simian virus 40 late transcription in vitro by a cellular factor binding the simian virus 40 21-base-pair repeat promoter element. Proc Natl Acad Sci USA 84: 6025-6029, 1987.

19. Swendeman SL, Spielholz C, Jenkins NA, Gilbert DJ, Copeland NG and Sheffery M: Characterization of the genomic structure, chromosomal location, promoter, and development expression of the alpha-globin transcription factor CP2. J Biol Chem 269: 11663-11671, 1994.

20. Cunningham JM, Vanin EF, Tran N, Valentine M and Jane SM: The human transcription factor CP2 (TFCP2), a component of the human gamma-globin stage selector protein, maps to chromosome region $12 \mathrm{q} 13$ and is within $250 \mathrm{~kb}$ of the NF-E2 gene. Genomics 30: 398-399, 1995.

21. Venkatesan K, McManus HR, Mello CC, Smith TF and Hansen U: Functional conservation between members of an ancient duplicated transcription factor family, LSF/Grainyhead. Nucleic Acids Res 31: 4304-4316, 2003.

22. Wilanowski T, Tuckfield A, Cerruti L, O'Connell S, Saint R, Parekh V, Tao J, Cunningham JM and Jane SM: A highly conserved novel family of mammalian developmental transcription factors related to Drosophila grainyhead. Mech Dev 114: 37-50, 2002

23. Traylor-Knowles N, Hansen U, Dubuc TQ, Martindale MQ Kaufman L and Finnerty JR: The evolutionary diversification of LSF and Grainyhead transcription factors preceded the radiation of basal animal lineages. BMC Evol Biol 10: 10, 2010.

24. Santhekadur PK, Rajasekaran D, Siddiq A, Gredler R, Chen D, Schaus SE, Hansen U, Fisher PB and Sarkar D: The transcription factor LSF: a novel oncogene for hepatocellular carcinoma. Am J Cancer Res 2: 269-285, 2012

25. Shirra MK and Hansen U: LSF and NTF-1 share a conserved DNA recognition motif yet require different oligomerization states to form a stable protein-DNA complex. J Biol Chem 273: 19260-19268, 1998

26. Kokoszynska K, Ostrowski J, Rychlewski L and Wyrwicz LS: The fold recognition of CP2 transcription factors gives new insights into the function and evolution of tumor suppressor protein p53. Cell Cycle 7: 2907-2915, 2008

27. Drouin EE, Schrader CE, Stavnezer J and Hansen U: The ubiquitously expressed DNA-binding protein late SV40 factor binds Ig switch regions and represses class switching to IgA. J Immunol 168: 2847-2856, 2002.

28. Zambrano N, Minopoli G, de Candia P and Russo T: The Fe65 adaptor protein interacts through its PID1 domain with the transcription factor CP2/LSF/LBP1. J Biol Chem 273: 20128-20133, 1998

29. Hansen U, Owens L and Saxena UH: Transcription factors LSF and E2Fs: tandem cyclists driving G0 to S? Cell Cycle 8: 2146-2151, 2009

30. Powell CM, Rudge TL, Zhu Q, Johnson LF and Hansen U: Inhibition of the mammalian transcription factor LSF induces S-phase-dependent apoptosis by downregulating thymidylate synthase expression. EMBO J 19: 4665-4675, 2000.
31. Manos MM, Ting Y, Wright DK, et al: The use of polymerase chain reaction amplification for the detection of genital human papillomaviruses. Cancer Cells 7: 209-214, 1989.

32. Yoshikawa H, Kawana T, Kitagawa K, Mizuno M, Yoshikura H and Iwamoto A: Detection and typing of multiple genital human papillomaviruses by DNA amplification with consensus primers. J Cancer Res 82: 524-531, 1991.

33. Daud II and Scott ME: Validation of reference genes in cervical cell samples from human papillomavirus-infected and -uninfected women for quantitative reverse transcription-PCR assays. Clin Vaccine Immunol 15: 1369-1373, 2008.

34. Wagner KU, Dierisseau P, Rucker EB, Robinson GW and Hennighausen L: Genomic architecture and transcriptional activation of the mouse and human tumor susceptibility gene TSG101: common types of shorter transcripts are true alternative splice variants. Oncogene 17: 2761-2770, 1998.

35. Liu RT, Huang CC, You HL, Chou FF, Hu CC, Chao FP, Chen CM and Cheng JT: Overexpression of tumor susceptibility gene TSG101 in human papillary thyroid carcinomas. Oncogene 21: 4830-4837, 2002.

36. Young TW, Mei FC, Rosen DG, Yang G, Li N, Liu J and Cheng X: Up-regulation of tumor susceptibility gene 101 protein in ovarian carcinomas revealed by proteomics analyses. Mol Cell Proteomics 6: 294-304, 2007

37. Kidd M, Nadler B, Mane S, Eick G, Malfertheiner M, Champaneria M, et al: GeneChip, geNorm and gastrointestinal tumors: novel reference genes for real-time PCR. Physiol Genomics 30: 363-370, 2007.

38. Swendeman SL, Spielholz C, Jenkins NA, Gilbert DJ, Copeland NG and Sheffery M: Characterization of the genomic structure, chromosomal location, promoter, and developmental expression of the B-globin transcription factor CP2. J Biol Chem 269: 11663-11671, 1994.

39. Ramamurthy L, Barbour V, Tuckfield A, Clouston DR, Topham D, Cunningham JM, et al: Targeted disruption of the $\mathrm{CP} 2$ gene, a member of the NTF family of transcription factors. J Biol Chem 276: 7836-7842, 2001.

40. Saxena UH, Powell CMH, Fecko JK, Cacioppo R, Chou HS, Cooper GM and Hansen U: Phosphorylation by cyclin C/cyclin-dependent kinase 2 following mitogenic stimulation of murine fibroblasts inhibits transcriptional activity of LSF during G1 progression. Mol Cell Biol 29: 2335-2345, 2009.

41. Coull JJ, Romerio F, Sun JM, Volker JL, Galvin KM, Davie JR, Shi Y, Hansen U and Margolis DM: The human factors YY1 and LSF repress the human immunodeficiency virus type 1 long terminal repeat via recruitment of histone deacetylase 1. J Virol 74: 6790-6799, 2000.

42. Lace MJ, Yamakawa Y, Ushikai M, Anson JR, Hangen TH and Turek LP: Cellular factor YY1 downregulates the human papillomavirus $16 \mathrm{E} 6 / \mathrm{E} 7$ promoter, P97, in vivo and in vitro from a negative element overlapping the transcrition-initiation site. J Gen Virol 90: 2402-2412, 2009.

43. Fan R, Chen P, Zhao D, Tonq JL, Li J and Liu F: Cooperation of deregulated Notch signaling and Ras pathway in human hepatocarcinogenesis. J Mol Histol 42: 473-481, 2011.

44. Zagouras P, Stifani S, Blaumeller CM, Carcangiu ML and Artavanis-Tsakonas S: Alterations in Notch signaling in neoplastic lesions of human cervix. Proc Natl Acad Sci USA 92: 6414-6418, 1995

45. Leethanakul C, Patel V, Gillespie J, Pallente M, Ensley JF, Koontongkaew S, Liotta LA, Emmert-Buck M and Gutkind JS: Distinct pattern of expression of differentiation and growth-related genes in squamous cell carcinomas of the head and neck revealed by use of laser capture microdissection and cDNA arrays. Oncogene 19: 3220-3224, 2000.

46. Westhoff B. Colaluca IN, D'Ario G, Donzelli M, Tosoni D, Volorio S, Pelosi G, Spaggiari L, Mazzarol G, Viale G, Pece S and Di Fiore PP, Alterations of the Notch pathway in lung cancer. Proc Natl Acad Sci USA 106: 22293-22298, 2009.

47. Zhang Y, Li B, Ji ZZ and Zheng PS: Notch 1 regulates the growth of human colon cancer. Cancer 116: 5207-5218, 2010.

48. Okuhashi Y, Nara N and Tohoda S: Effects of gamma-secretase inhibitors on the growth of leukemia cells. Anticancer Res 30: 495-498, 2010.

49. Shlomai A: Targeting late SV40 factor: is the achilles heel of hepatocarcinogenesis revealed? World J Gastroenterol 18: 6709-6711, 2012

50. Veljkovic J and Hansen U: Lineage-specific and ubiquitous biological roles of the mammalian transcription factor LSF. Gene 343: 23-40, 2004 